\title{
Lateralized repetition priming for familiar faces: Evidence for asymmetric interhemispheric cooperation
}

\author{
Victoria J. Bourne \\ Department of Psychology, University of Dundee, Dundee, UK \\ Graham J. Hole \\ University of Sussex, Brighton, UK
}

\begin{abstract}
Repetition priming refers to facilitated recognition of stimuli that have been seen previously. Although a great deal of work has examined the properties of repetition priming for familiar faces, little has examined the neuroanatomical basis of the effect. Two experiments are presented in this paper that combine the repetition priming paradigm with a divided visual field methodology to examine lateralized recognition of familiar faces. In the first experiment participants were presented with prime faces unilaterally to each visual field and target faces foveally. A significant priming effect was found for prime faces presented to the right hemisphere, but not for prime faces presented to the left hemisphere. In Experiment 2, prime and target faces were presented unilaterally, either to the same visual field or to the opposite visual field (i.e., either within hemisphere or across hemispheres). A significant priming effect was found for the within right hemisphere condition, but not for the within left hemisphere condition, replicating the findings of the first experiment. Priming was also found in both of the across hemispheres conditions, suggesting that interhemispheric cooperation occurs to aid recognition. Taken in combination these experiments provide two main findings. First, an asymmetric repetition priming effect was found, possibly as a result of asymmetric levels of activation following recognition of a prime face, with greater priming occurring within the right hemisphere. Second, there is evidence for asymmetric interhemispheric cooperation with transfer of information from the right hemisphere to the left hemisphere to facilitate recognition.
\end{abstract}

Repetition priming refers to the phenomenon whereby repeated presentation of a visual stimulus causes it to be recognized faster on subsequent trials. The existence of repetition priming for faces is now well established (e.g., Lewis \& Ellis, 1999, 2000) and has been found to last over a period of days (Lewis \& Ellis, 1999) or months.

"Episodic" accounts of repetition priming for faces attempt to explain it within the framework of a general explanation for priming phenomena. Jacoby (1983), for example, suggests that an

Correspondence should be addressed to Victoria Bourne, Department of Psychology, The University of Dundee, Dundee, DD1 4HN, Scotland, UK. Email: v.bourne@dundee.ac.uk

We would like to thank Stefan Schweinberger and an anonymous reviewer for insightful and helpful comments on an earlier version of this paper. Thanks also to Daniel B. Wright for advice and assistance in calculating the within-subject confidence intervals presented in the figures. 
initial encounter with a stimulus (whether this is a face or a word) produces an episodic memory trace. A subsequent encounter with the same stimulus reactivates the existing memory trace and thus facilitates recognition. Roediger and Blaxton's (1987) "transfer-appropriate processing" account of repetition priming suggests that the second encounter with a stimulus reinstates the processing demands of the initial encounter. The more overlap there is between the mental operations performed at the two encounters with the stimulus, the greater the priming effect. Although these theories differ in detail, they both predict that priming will be affected by the level of similarity in processing performed at the first and second encounters with a stimulus.

In contrast, "structural" accounts of face priming suggest that it reflects the operation of cognitive processes that are more or less dedicated to this class of stimuli. The most popular structural explanation for face repetition priming comes from Burton, Bruce, and Johnston's (1990) interactive activation and competition (IAC) model of person recognition. This suggests that there are three sequential, functional components within the processing and recognition of a face. When a face is initially encountered it is structurally encoded; this provides a representation or description of the face. Each known face is represented in the cognitive system by a "face recognition unit" (FRU), which contains representations of different views of that face. If the encountered representation matches a stored representation, that FRU will be activated, and the face will be recognized as belonging to a familiar person. The activated FRU then triggers a "person identity node" (PIN), which subsequently accesses semantic information about the recognized person and their name. Burton et al. suggest that repetition priming occurs because presentation of a familiar face strengthens the links between the FRU for that face and its associated PIN.

The IAC model can accommodate many observed repetition priming phenomena, including some that are not easily explained by an episodic account. For example, the IAC model explains why repetition priming for unfamiliar faces is either nonexistent (e.g., Campbell \& de Haan, 1998; Ellis, Young, \& Flude, 1990), or very short-lived (Bentin \& Moscovitch, 1988): There are no PINs for unfamiliar faces, and so there are no FRU-PIN links to be strengthened. It also explains why prior exposure to a face primes identity decisions, but does not prime judgements about a face's gender or expression; the latter would not involve FRUs or PINs (Ellis et al., 1990). Two observations in particular seem easier to explain in terms of the IAC model than by an episodic account of priming. First, faces show partto-whole priming, explicable in terms of partial activation of the relevant FRU. Second, faces act as primes only if they are spontaneously recognized (Brunas-Wagstaff, Young, \& Ellis, 1992; Johnston, Barry, \& Williams, 1996). The Burton et al. (1990) model predicts that unless there is activation of both FRU and PIN, strengthening of the links between them cannot occur. Consequently, unrecognized faces cannot produce priming effects, because they do not activate any FRUs.

The Burton et al. (1990) IAC model says little about the nature of the FRUs and what constitutes adequate stimulation for them. It is claimed that FRUs "will become active when any (recognisable) view of the appropriate face is seen" (Burton et al., 1990, p. 361), a view echoed by Burton, Young, Bruce, Johnston, and Ellis (1991) and Bruce, Burton, Carson, Hanna, and Mason (1994). The model suggests that FRUs might be fed by "feature"-recognizing units, and it is pointed out that these "features" may include configurational properties as well as parts such as eyes and mouths.

A popular distinction in the face-processing literature has been between "featural" and "configural" modes of processing (e.g., Collishaw \& Hole, 2000; Bartlett \& Searcy, 1993: See Rakover, 2002, for a review of these concepts). However, such a division suffers two major problems. The first is what Rakover (2002) calls the "intrinsic connection" between features and configurations (change one, and you inevitably affect the other). The other is the fact that we do not really know what constitute the "primitives" of 
face perception: An eye may appear to be a "feature" to us because of its perceptual salience in a face, but that does not necessarily mean that the visual system regards it in the same way. It is unsatisfactory to base our classification of "features" solely in terms of how obvious they are to us. One way around this problem is to use statistical techniques such as principal components analysis (PCA) to provide candidate dimensions for encoding and representing faces (e.g., Hancock, Burton, \& Bruce, 1996). Another way may be to capitalize on hemispheric differences in processing style.

A growing body of evidence suggests that face processing and recognition are typically lateralized to the right hemisphere $(\mathrm{RH})$. This evidence comes from both clinical and nonclinical populations. Prosopagnosia, a neuropsychological disorder resulting in impaired face recognition, has traditionally been seen to result from unilateral RH lesions (e.g., De Renzi \& Spinnler, 1966; Marotta, McKeeff, \& Behrmann, 2002; Uttner, Bliem, \& Danek, 2002). Evidence taken from nonclinical populations also suggests that the $\mathrm{RH}$ is dominant for face processing and recognition. This has been demonstrated using both behavioural methods (e.g., Hillger \& Koenig, 1991; Magnussen, Sunde, \& Dyrnes, 1994; Young, Hay, McWeeny, Ellis, \& Barry, 1985) and neuroimaging techniques (e.g., Haxby et al., 1999; Kanwisher, McDermott, \& Chun, 1997). Although RH superiority for face processing and recognition is widely accepted, a great deal of evidence now suggests that the left hemisphere (LH) also has some capacity for face processing and recognition (e.g., Damasio, Damasio, \& VanHosen, 1982; Dubois et al., 1999; McCarthy, Puce, Gore, \& Allison, 1997; Puce, Allison, Asgari, Gore, \& McCarthy, 1996). The question thus arises: What is the anatomical basis of the observed repetition priming effects for faces?

A number of studies have examined repetition priming for familiar face recognition using event related potentials (ERPs). Such studies have reliably found ERP modulation from immediate repetition of faces resulting in increased negativity with a latency of $200-300 \mathrm{~ms}$ (N250r) in right inferior temporal areas (Begleiter, Porjesz, \& Wang, 1995; Pfütze, Sommer, \& Schweinberger, 2002; Schweinberger, Pfütze, \& Sommer, 1995; Schweinberger, Pickering, Burton, \& Kaufmann, 2002). This lateralized effect is consistent with the previously discussed evidence supporting a $\mathrm{RH}$ superiority for face processing and recognition. Although these experiments suggest that the facilitated effect found in the face repetition priming effect results from increased activity in the $\mathrm{RH}$, they only consider the lateralization of the priming effect when the stimuli are presented bilaterally. The two experiments presented in this paper use the repetition priming effect in combination with a behavioural, divided visual field methodology. The logic behind this methodology is that a stimulus presented to one visual field is initially received and processed by the contralateral hemisphere. Therefore a stimulus presented to the left visual field is initially received and processed by the $\mathrm{RH}$, and a stimulus presented to the right visual field by the LH. As such, any visual field effects identified may be taken to reflect distinctions in hemispheric functioning.

Although it appears that no research to date has examined lateralization for face processing using repetition priming, this technique has been used to examine other lateralized processes. A small number of studies have used semantic priming in an attempt to further understand the lateralization of language and semantic processing (e.g., Abernethy \& Coney, 1996; Berger, 1988; Collins, 1999; Collins \& Coney, 1998; Koivisto \& Hämäläinen, 2002; Koivisto \& Laine, 2000). Such studies have presented primes unilaterally, followed by semantically related target words presented either unilaterally or bilaterally, and have found robust and replicable laterality effects. Two main findings have arisen from these experiments. First, when unilaterally presented primes were followed by bilaterally presented targets, more priming occurred when primes were presented initially to the hemisphere that is specialized for the task. Thus, when target words were presented bilaterally, more priming was produced by primes presented to the right visual field 
(LH), than by primes presented to the left visual field (RH; Abernethy \& Coney, 1996; Berger, 1988; Collins \& Coney, 1998). Second, when both the prime and the target were presented unilaterally, more priming was found when the prime was presented to the specialized (left) hemisphere and the target word to the nonspecialized (right) hemisphere than vice versa (Abernethy \& Coney, 1996; Berger, 1988; Collins, 1999; Collins \& Coney, 1998; Koivisto \& Hämäläinen, 2002). Such research provides evidence for lateralized priming effects that are in line with the lateralized specializations typically identified for processing particular types of stimulus (i.e., LH for language). With such evidence in mind it might also be suggested that faces would show a lateralized priming effect, with greater priming occurring when presented to the specialized $\mathrm{RH}$ than when presented to the LH. This issue is examined in this paper.

An examination of the anatomical locus of face processing and repetition priming may help in understanding more about the nature of FRUs. The following experiments use a divided-visualfield technique in order to study the lateralization of repetition priming effects in normal individuals. There are a number of reasons why this is interesting. The main one is that it provides information on the anatomical locus of face repetition priming effects. The second is that there is already an extensive body of knowledge about how the two hemispheres differ in processing mode. The right hemisphere tends to process stimuli in a more holistic, global manner, while the left hemisphere adopts a more piecemeal and local processing style. It is tempting to speculate that the right hemisphere processes faces configurally, while the left hemisphere processes faces more featurally. Given this distinction, a method that enables facial stimuli to be selectively processed by one mode or the other may sidestep the conceptual difficulties of distinguishing between "featural" and "configural" processing. Repetition priming of lateralized stimuli is one such method. Third, the results from lateralized repetition priming studies may be informative with respect to choosing between structural and episodic accounts of repetition priming. Episodic accounts would predict that most face priming will be obtained when the face is processed by the same hemisphere each time, since it will then have been subjected to the same type of processing (featural or configural) in each case. Acrosshemisphere priming (e.g., prime to left hemisphere and target to right hemisphere) should be less effective than within-hemisphere priming, both because the initial learning experience would be different on both occasions (a face to the right visual field on the first occasion and to the left visual field on the second occasion) and because the type of processing of the face would be likely to be different on both occasions. In contrast, the IAC model predicts similar amounts of priming in each case.

The two experiments presented in this paper use a similar technique to examine the lateralization of the face priming effect. In the first experiment prime faces were presented unilaterally to either the left visual field-right hemisphere (LVF-RH) or the right visual field-left hemisphere (RVF-LH), and target faces were presented foveally at the central fixation point and therefore were projected bilaterally. The second experiment provides a more detailed examination of the lateralized repetition priming effect for face recognition. In this experiment primes were again presented unilaterally to either the $\mathrm{LVF}-\mathrm{RH}$ or the RVF-LH, but the target faces were also presented unilaterally, either to the same visual field as the prime face (within hemisphere) or to the other visual field (across hemispheres).

\section{EXPERIMENT 1: UNILATERAL REPETITION PRIMING}

In this experiment prime faces were presented unilaterally, either to the LVF-RH or to the RVF-LH. Subsequent target faces were presented foveally at the central fixation point. Previous studies using a similar technique to examine the lateralization of language and semantic processing have found a greater semantic priming effect when primes were presented to the hemisphere 
specialized in that mode of processing (Abernethy \& Coney, 1996; Berger, 1988; Collins \& Coney, 1998). It is predicted that face primes presented to the LVF-RH will elicit a greater priming effect than will face primes presented to the RVF-LH due to the typically found $\mathrm{RH}$ superiority for face recognition.

\section{Method}

\section{Participants}

A total of 39 students $(9$ males) from the University of Sussex participated. Mean age was 22.6 years $(S D=3.8)$. Participants were righthanded by self-report. All completed a 14-item handedness questionnaire (adapted from Dorthe, Blumenthal, Jason, \& Lantz, 1995) which measured handedness on a continuum from -1 (strongly left handed) to +1 (strongly right handed). All of the participants had positive handedness quotients (mean $=0.6, S D=0.4$ ) indicating that all were strongly right handed. Participants were also given a chimeric faces test as a test of cerebral asymmetry (adapted from Levy, Heller, Banich, \& Burton, 1983). This measure provides an asymmetry quotient ranging from -1 ( $\mathrm{LH}$ superiority for a face-processing task) to +1 ( $\mathrm{RH}$ superiority for a face-processing task). The mean laterality quotient was positive (mean $=0.3, S D=0.4$ ). The handedness and cerebral asymmetry measures were not correlated $(r=.05, p=.759)$.

\section{Design}

A total of 20 faces were presented in the prime phase, half of which were famous, and half of which were not famous. Of these, 10 were presented in the LVF-RH, and 10 were presented in the RVF-LH. In the target phase all 20 faces were presented again, plus an additional 10 unprimed faces, half of which were famous, and half of which were not famous. Stimuli were fully counterbalanced across the conditions. On both the prime and the target phases of the experiment, the latency and accuracy of each response were recorded. Only correct responses to faces were analysed. Analyses were performed on difference scores obtained by subtracting performance in the unprimed condition from that in the primed condition in the target phase of the experiment. Therefore, for latency, a negative difference suggests a decrease in reaction time and hence a priming effect. For accuracy, a positive difference suggests an improvement in performance. Accuracy was measured using $d^{\prime}$.

\section{Stimuli}

All faces were of white males with no facial hair or glasses. Faces were presented in greyscale on a white background and were $4.4^{\circ}$ wide at the viewing distance used $(30 \mathrm{~cm})$. Famous faces were selected for inclusion following a questionnaire study administered to 100 undergraduate students, which asked them to list 20 white famous males. The most frequently named celebrities were used in the experiment. Following the experiment each participant completed a questionnaire containing all of the famous faces used in the experiment, plus 10 not-famous distractor faces. For each face they had to say whether the person was famous or not and give the person's name. If a famous face was not correctly identified in this questionnaire the corresponding trial was discarded from the analysis.

\section{Procedure}

Participants sat at a computer with their head placed on a chin rest, to limit head movements and to keep their eyes $30 \mathrm{~cm}$ from the screen. The prime phase of the experiment was completed first. Each trial consisted of four events (see Figure 1). Participants saw a "Get ready" prompt for 2,000 ms. They then saw a single upper-case consonant for $750 \mathrm{~ms}$, which they had to report verbally. This was done to ensure that participants were fixating the centre of the screen on each trial immediately before each face stimulus was presented. If the letter was reported incorrectly, or if the participant delayed reporting it, the trial was not included in the subsequent analysis. Next, the face was presented for $120 \mathrm{~ms}$, with its inside edge $4^{\circ}$ from the central fixation point. The duration and position of stimulus presentation were selected to ensure unilateral 

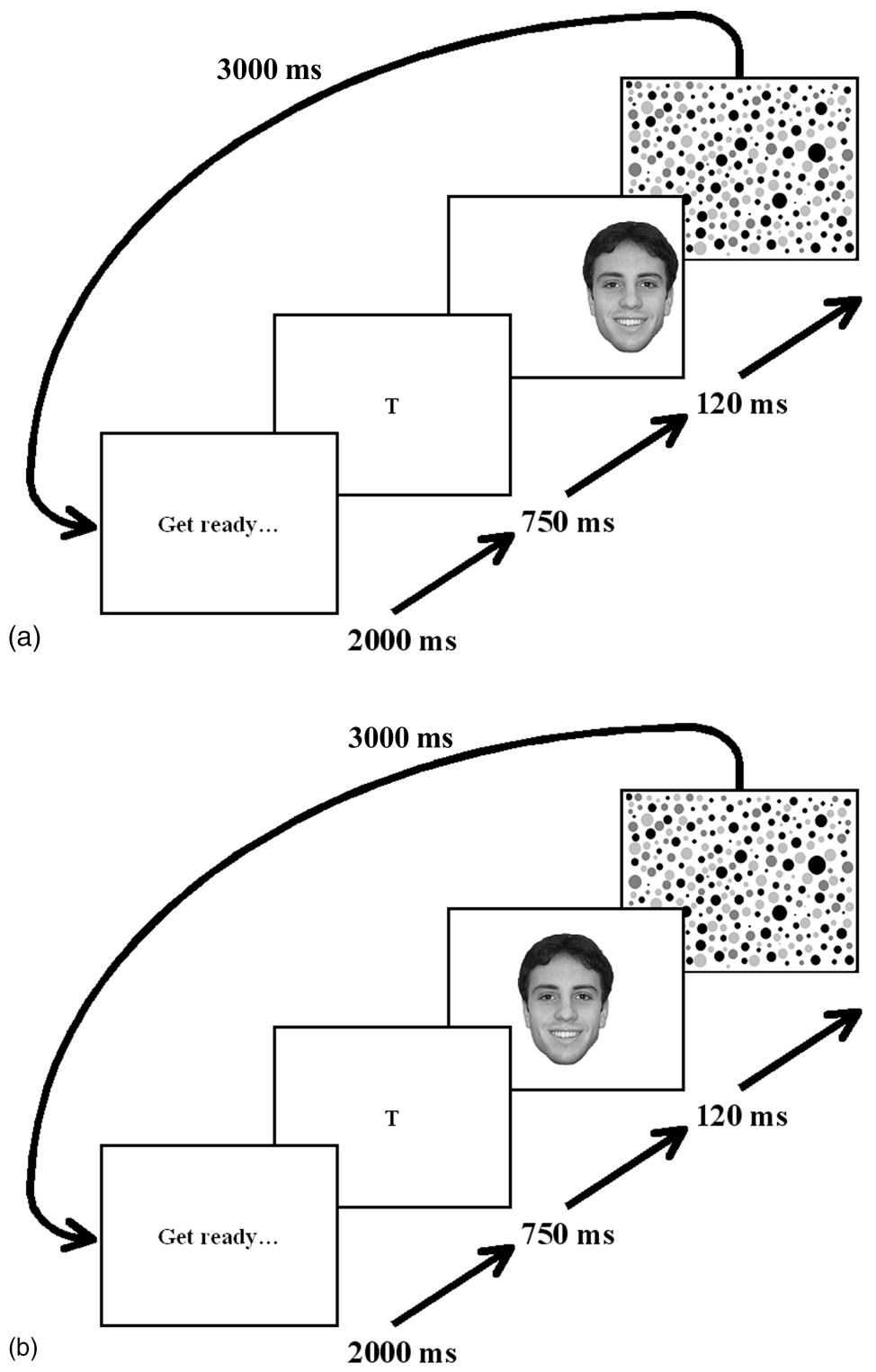

Figure 1. Trial summary for the unilateral prime (a) and foveal target (b) phases of Experiment 1.

presentation in this phase of the experiment (see Young, 1982). A mask of overlapping greyscale circles was then presented until the participant responded. Participants responded using the computer mouse: Half responded with a left click for "famous" responses and a right click for "not famous", and the rest responded with a left click for "not famous" and a right click for "famous". A 3,000-ms interval occurred before the next trial began. After completing the prime phase of the experiment, participants were given a short break of around 3 minutes. They then completed the target phase of the experiment. The procedure was identical to that of the prime phase other than 
that all of the faces were presented foveally at the central fixation point. Participants were unaware that the two phases of the experiment were related and were not told that they would be seeing the same faces in the target phase. Participants completed 10 practice trials before each phase of the experiment. Stimulus presentation was controlled and randomized using Superlab 2.0 software. The randomization sequence differed between the prime and target phases, and stimuli were fully counterbalanced across visual fields.

\section{Results and discussion}

For famous face recognition, primes presented to the LVF-RH caused significantly more priming than those presented to the RVF-LH, $t(38)=4.74, p<.001$ (see Table and Figure 2). One-sample $t$ tests showed a significant priming effect for primes presented to the $\mathrm{LVF}-\mathrm{RH}$, $t(38)=3.96, p<.001$, but not for those presented to the RVF-LH, $t(38)=1.71, p=.240$. No significant differences were identified in the analyses of latency for the nonfamous faces or in the accuracy data ( $t<1.3$ for all comparisons).

The results of this experiment suggest that faces presented unilaterally to the $\mathrm{LVF}-\mathrm{RH}$ cause a significant priming effect, resulting in faster recognition of famous faces. This effect was not replicated for prime faces presented to the RVFLH. This finding is consistent with previous research demonstrating a $\mathrm{RH}$ superiority for face

Table 1. Mean reaction times and error rates for Experiment 1

\begin{tabular}{ccrr}
\hline & & Mean & SD \\
\hline Mean reaction times $^{2}$ & LVF-RH & 571.9 & 208.2 \\
to famous faces $^{\mathrm{a}}$ & RVF-LH & 666.6 & 263.5 \\
& Unprimed & 651.5 & 256.5 \\
Mean reaction times $_{\text {to not-famous faces }}{ }^{\mathrm{a}}$ & LVF-RH & 574.1 & 166.0 \\
& RVF-LH & 553.6 & 142.9 \\
Error rates $^{\mathrm{b}}$ & Unprimed & 588.2 & 196.6 \\
& LVF-RH & 0.6 & 0.7 \\
& RVF-LH & 0.7 & 0.9 \\
& Unprimed & 0.5 & 0.8 \\
\hline
\end{tabular}

${ }^{\mathrm{a}}$ In ms. ${ }^{\mathrm{b}}$ Number incorrect.

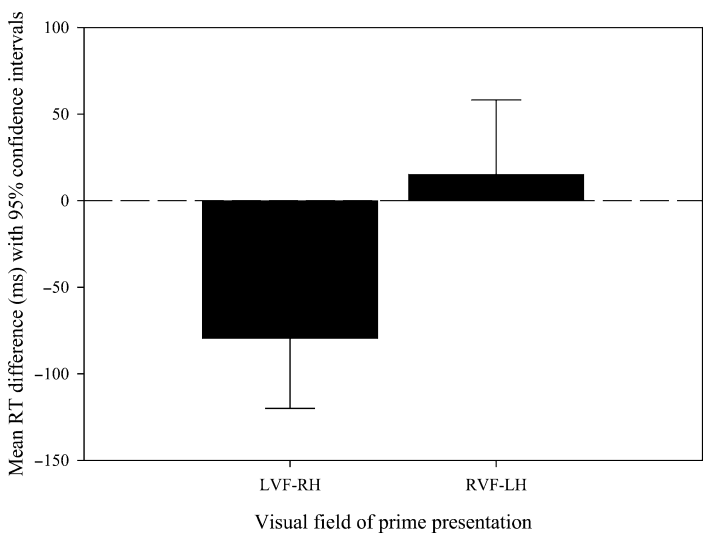

Figure 2. Mean reaction time difference to famous faces (with 95\% confidence interval) in Experiment 1. Within-subjects confidence intervals were calculated according to Loftus and Masson's method (Loftus E Masson, 1994).

recognition (e.g., De Renzi \& Spinnler, 1966; Haxby et al., 1999; Hillger \& Koenig, 1991; Marotta et al., 2002). It is also consistent with the previous research using lateralized semantic word priming, which also found that priming effects only occurred for primes presented to the hemisphere specialized for the given task (Abernethy \& Coney, 1996; Berger, 1988; Collins \& Coney, 1998).

It is interesting that no priming occurred from prime faces presented to the RVF-LH. Although this is consistent with the findings of the lateralized semantic word-processing experiments, it seems inconsistent with previous research, which has suggested that the LH is capable of face processing and recognition, albeit with less efficiency than the RH (e.g., Damasio et al., 1982; Dubois et al., 1999; McCarthy et al., 1997; Puce et al., 1996). There are, however, some differences between the aspects of face processing and recognition that are being tapped into in previous research and those in this experiment. Most previous experiments have only examined what occurs in each hemisphere until the point of recognition. These experiments consider what occurs in the brain after recognition has occurred and how this affects subsequent recognition of the target face. 
The IAC model of face processing and recognition (Burton et al., 1990) explains the face repetition priming effect in terms of strengthened links between FRU and PIN. After the face has been recognized, the excitatory links remain above resting level, and therefore if the face is seen again recognition occurs faster as less activation is necessary to trigger a familiarity response. It may be that there is hemispheric asymmetry in the time taken for the excitatory links to return to resting. As the RH is dominant for face processing and recognition it may be that the level of activation in the $\mathrm{RH}$ remains high for some time after recognition, whereas levels of activation in the LH may return to resting levels quickly after recognition.

\section{EXPERIMENT 2: WITHIN- AND ACROSS-HEMISPHERE REPETITION PRIMING}

The previous experiment provided support for a lateralized repetition priming effect for face recognition. However, its findings seemed to suggest that face primes presented to the RVFLH had no subsequent priming effect. In Experiment 2, target faces were presented unilaterally rather than foveally. Introducing this difference allows for a more detailed examination of lateralized priming contained within one hemisphere, when the prime and target are both presented to the same visual field. The inclusion of across-hemisphere priming conditions may also provide interesting findings regarding the role of interhemispheric cooperation (IHC) in face processing and recognition in everyday viewing situations.

Previous experiments using lateralized semantic word priming have compared within- and across-hemisphere priming (Abernethy \& Coney, 1996; Berger, 1988; Collins, 1999; Collins \& Coney, 1998; Koivisto \& Hämäläinen, 2002). Comparing priming within each visual field, such studies have found the largest priming effect within the hemisphere specialized for the task being completed. For the across hemisphere conditions they have found most priming when the prime was presented to the hemisphere specialized for the task, and the target was presented to the hemisphere not specialized for the task. Therefore, for lateralized face repetition priming, it might be predicted that the greatest priming effect will be found in the within LVF$\mathrm{RH}$ condition where both the prime and the target are presented to the $\mathrm{LVF}-\mathrm{RH}$. In the across priming conditions it is predicted that the greatest priming will occur in the LVF-RH to $\mathrm{RVF}-\mathrm{LH}$ condition, where the prime is presented to the $\mathrm{LVF}-\mathrm{RH}$ and the target to the RVF-LH.

Examining the within and across visual field conditions will enable us to drawn further conclusions regarding the lateralized processing and recognition of face, both by each hemisphere in isolation and by the two hemispheres in cooperation. The two within hemisphere conditions will provide evidence for processing by each hemisphere in isolation, as the information will remain contained within each hemisphere with no need for IHC. The two across visual field conditions will also provide evidence regarding $\mathrm{IHC}$, as any priming effect in these conditions can only have occurred by the information being passed between the hemispheres. If no IHC occurs then no priming should occur in the across visual field conditions. However, if priming does occur this will suggest that IHC does occur in order to enable primes presented to one hemisphere to cause a priming effect when the target is presented to the other hemisphere.

\section{Method}

\section{Participants}

A total of 35 students $(13$ males) from the University of Sussex participated. Mean age was 21.3 years $(S D=3.4)$. None of these had participated in the previous experiment. All of the participants had positive handedness quotients (mean $=0.6, S D=0.3$ ) indicating that all were strongly right-handed. The mean laterality quotient was also positive (mean $=0.3, S D=0.4$ ). 
These two behavioural measures were not correlated $(r=.03, p=.884)$.

\section{Design}

A total of 40 faces were unilaterally presented in the prime phase of the experiment with 10 presented in each condition, 5 famous and 5 not famous (see Figure 3). In the target phase the same 40 faces were presented unilaterally with 20 presented in the same visual field as that of the prime face (within hemisphere condition) and 20 presented in the opposite visual field to that of the prime face (across hemisphere condition). In the target phase 20 unprimed faces were also presented unilaterally, 10 to each visual field, of which 5 were famous, and 5 were not famous. The randomization sequence differed between the prime and target phases, and stimuli were fully counterbalanced across visual fields.

\section{Stimuli and procedure}

Faces were selected and presented in the same way as in Experiment 1. The procedure was the same as that for the previous experiment, other than for one change to the target phase. In this experiment target faces were presented unilaterally $4^{\circ}$ from the central fixation point (see Figure 4).

\section{Results and discussion}

For the famous face recognition reaction time analysis (see Table 2 and Figure 5), the main effect of visual field of target presentation was significant, with faces presented in the LVF-RH
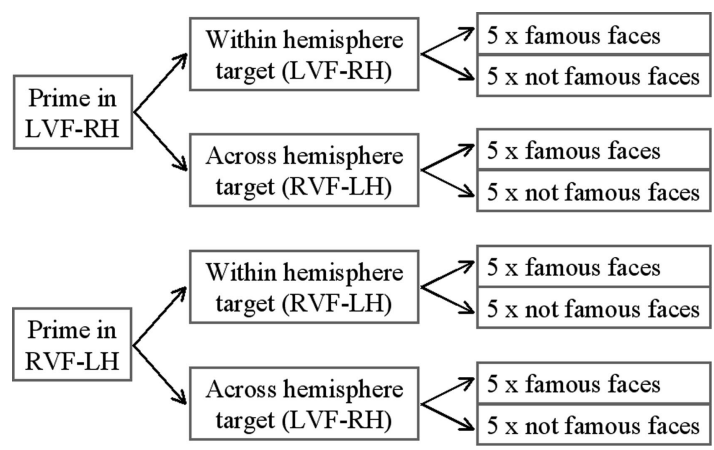

Figure 3. Experimental design for prime phase of Experiment 2.
Table 2. Mean reaction times and error rates for Experiment 2

\begin{tabular}{clrr}
\hline & & Mean & SD \\
\hline Mean reaction & LVF-RH to LVF-RH & 560.1 & 121.0 \\
time to & LVF-RH to RVF-LH & 584.6 & 147.1 \\
famous faces ${ }^{\mathrm{a}}$ & RVF-LH to LVF-RH & 616.8 & 150.6 \\
& RVF-LH to RVF-LH & 653.6 & 272.3 \\
& Unprimed to LVF-RH & 699.4 & 185.4 \\
Mean reaction & Unprimed to RVF-LH & 634.9 & 160.9 \\
time to & LVF-RH to LVF-RH & 630.1 & 154.8 \\
not famous & LVF-RH to RVF-LH & 621.7 & 150.2 \\
faces & RVF-LH to LVF-RH & 647.1 & 136.6 \\
& RVF-LH to RVF-LH & 620.8 & 176.7 \\
& Unprimed to LVF-RH & 601.2 & 120.0 \\
Error rates ${ }^{b}$ & Unprimed to RVF-LH & 619.8 & 134.4 \\
& LVF-RH to LVF-RH & 1.2 & 1.2 \\
& LVF-RH to RVF-LH & 0.8 & 0.9 \\
& RVF-LH to LVF-RH & 0.7 & 1.0 \\
& RVF-LH to RVF-LH & 1.0 & 1.2 \\
& Unprimed to LVF-RH & 1.1 & 1.3 \\
& Unprimed to RVF-LH & 1.6 & 1.2 \\
\hline
\end{tabular}

${ }^{\mathrm{a}}$ In ms. ${ }^{\mathrm{b}}$ Number incorrect.

causing a greater priming effect than faces presented to the RVF-LH, $F(1,34)=3.5$, $p=.035$. The main effect of within versus across condition was not significant, $F(1,34)=0.14$, $p=.356$. The visual field of target presentation by within versus across condition interaction was significant, $F(1,34)=6.71, p=.007$. This interaction was examined using simple main effects. The examination was broken down by comparing the within and across conditions for each visual field of target presentation. This comparison will reveal whether the transfer of information between the two hemispheres (the across condition) increases or decreases the priming effect that occurs within hemisphere. When the target was presented in the LVF-RH there was a priming effect in both the within and across conditions, but the effect was significantly larger in the within condition $(p=.024)$, suggesting that the transfer of information between the two hemispheres reduces the priming effect. When the target was presented to the RVF-LH there was a priming effect in the across condition, but not in the within condition $(p=.050)$, suggesting that the priming effect in the $\mathrm{LH}$ is facilitated by the transfer of information from the $\mathrm{RH}$. One- 

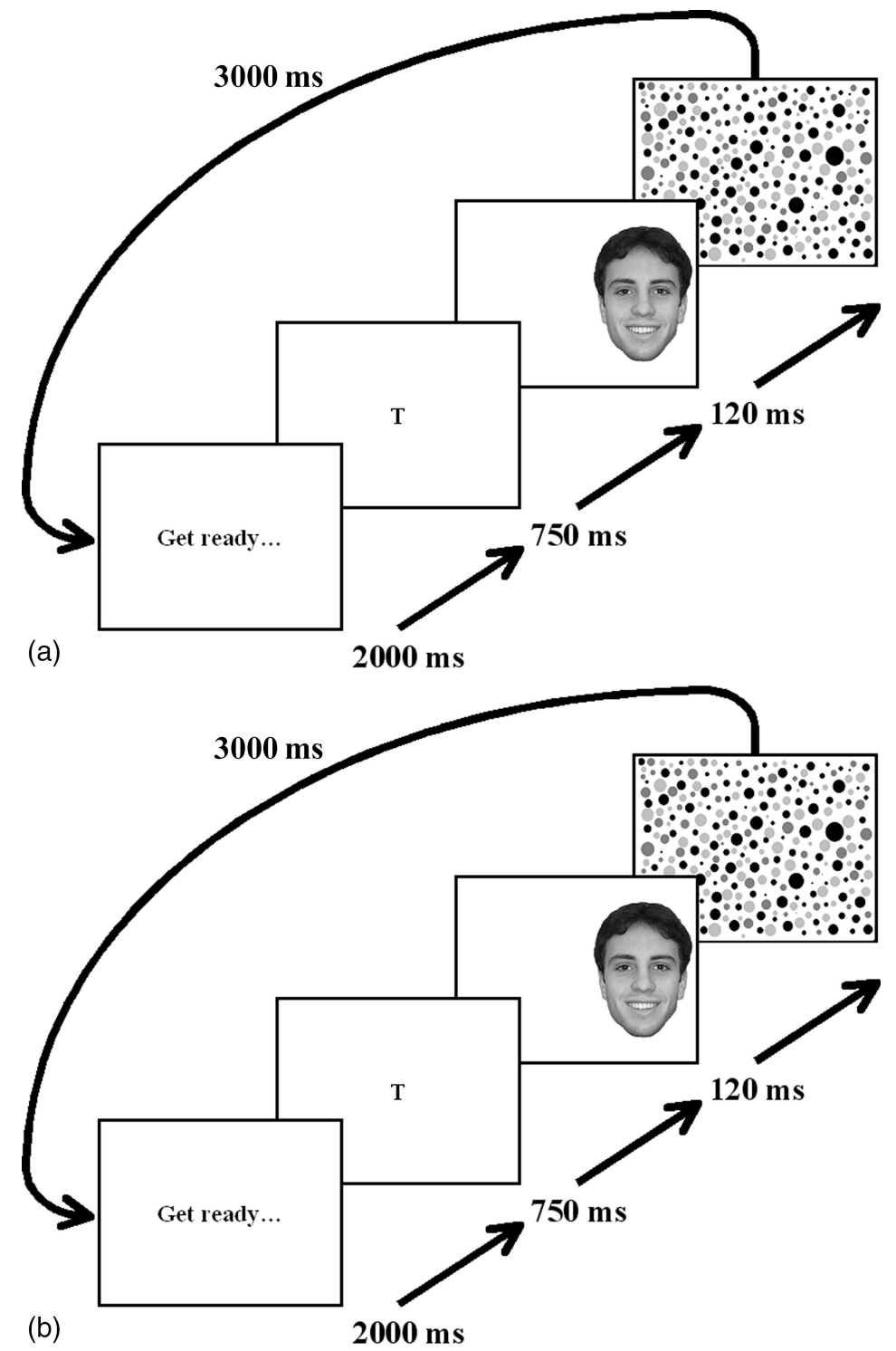

Figure 4. Trials summary for the unilateral prime (a) and unilateral target (b) phases of Experiment 2. The example shows a within RVF-LH trial.

sample $t$ tests showed a significant priming effect in the within $\mathrm{LVF}-\mathrm{RH}$ condition, $t(34)=4.61$, $p<.001$, but not in the within RVF-LH condition, $t(34)=0.37, p=.356$. Significant priming was found in both the across visual fields conditions: across to LVF-RH, $t(34)=4.12, p<.001$; across to $\mathrm{RVF}-\mathrm{LH}, t(34)=2.16, p=.019$.
No significant differences were found for the not-famous latency analyses or the accuracy analyses $(F<1.9, t<1.7$, for all comparisons).

The findings of this experiment provide a number of insights into the lateralization of face processing and recognition and the role of IHC in these processes. In the two within visual field 


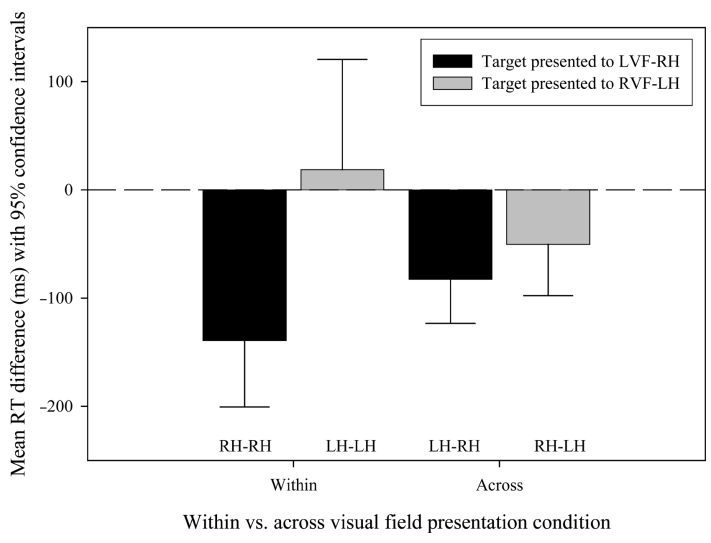

Figure 5. Mean reaction time difference to famous faces (with 95\% confidence intervals) in Experiment 2. Within-subjects confidence intervals were calculated according to Loftus and Masson's method (Loftus E Masson, 1994).

conditions, a large priming effect occurred in the within $\mathrm{LVF}-\mathrm{RH}$ condition, but no priming was found in the within RVF-LH condition. This replicates the findings of the previous experiment and supports the suggestion that greater priming occurs from the hemisphere specialized for the given task (Abernethy \& Coney, 1996; Berger, 1988; Collins, 1999; Collins \& Coney, 1998; Koivisto \& Hämäläinen, 2002).

For both of the across visual field conditions there was a significant priming effect. This finding suggests that IHC exists to aid face processing and recognition, as a face stimulus presented unilaterally to one hemisphere has a priming effect on its subsequent presentation to the other hemisphere. Such an effect can only occur if the information is transferred between the hemispheres. The finding of an across hemisphere priming effect is consistent with previous research that provides evidence for the existence of IHC to aid recognition (Compton, 2002; Mohr, Landgrebe, \& Schweinberger, 2002; Schweinberger, Baird, Blumler, Kaufmann, \& Mohr, 2003). Although we found evidence for IHC, a facilitated priming effect was only found when the target was presented to the RVF-LH. This suggests that IHC is asymmetric and only occurs in the direction of $\mathrm{RH}$ to $\mathrm{LH}$. This asymmetry can be easily explained in terms of hemispheric superiority for face recognition. As the $\mathrm{RH}$ is superior it is unlikely to need assistance from the $\mathrm{LH}$, whereas aid from the $\mathrm{RH}$ is likely to improve performance of the $\mathrm{LH}$ as it does not show a superiority for face recognition.

The first experiment presented in this paper found no priming effect from primes presented to the LH. This finding was also replicated in the within $\mathrm{RVF}-\mathrm{LH}$ priming condition in this experiment and is consistent with the suggestion made in the discussion of the previous experiment, that there might be hemispheric asymmetries in the time course of excitatory activation following recognition, with $\mathrm{LH}$ activation following recognition falling to resting levels soon after the recognition decision has been made.

\section{GENERAL DISCUSSION}

The experiments presented in this paper examined lateralization of face recognition using a lateralized repetition priming paradigm. Two main findings emerged. First, both experiments found a significant priming effect from prime faces presented to the $\mathrm{RH}$, but no priming effect from prime faces presented to the LH. Second, evidence for the existence of IHC to aid face recognition was found in the across hemisphere priming conditions of the second experiment.

The present patterns of results have some implications for current theories of how repetition priming occurs. As mentioned in the Introduction, although Burton et al.'s (1990) IAC model has been the most popular explanation for repetition priming of faces, accounts in terms of the reactivation of episodic memory traces (e.g., Jacoby, 1983; Logan, 1990) have also been proposed. Arguing in favour of an instance-based account of face repetition priming, Goshen-Gottstein and Ganel (2000) found evidence for repetition priming of unfamiliar (once-seen) faces-but only if participants were encouraged to attend to the internal facial features of the unfamiliar faces that were to act as primes. They suggest that "stimuli must be processed in their entirety, for repetition effects to 
emerge" (p. 1200), and that the failure to find unfamiliar-face repetition priming in previous studies occurred because participants were not encouraged to process the faces as perceptual wholes.

The present results offer little support for Goshen-Gottstein and Ganel's (2000) hypothesis. First, no significant repetition priming was found for unfamiliar faces in any condition, in line with most previous studies. Goshen-Gottstein and Ganel could plausibly argue that in previous unfamiliar-face repetition priming experiments, participants were being encouraged to process the prime faces incompletely (e.g., by attending mainly to external facial features in order to make sex judgements). However, there is no reason why our participants should have processed the unfamiliar faces in this way. (In fact, previous research suggests that very brief stimulus presentations encourage a holistic mode of face processing-see Hole, 1994.) Second, in Experiment 2 of the present study, priming did not occur if the prime and target were both presented to the left hemisphere (when one would expect there to be good overlap between the prime and target in terms of perceptual properties). In contrast, priming did occur even when the prime was presented to the left hemisphere (and hence processed in a piecemeal, featural manner), and the target was displayed to the right hemisphere (and hence processed configurally). If priming effects are due to similarity between prime and target, as Goshen-Gottstein and Ganel suggest, then we might have expected to find priming for famous faces in the wholly left hemisphere condition, and for both famous and nonfamous faces in the wholly right hemisphere condition-in practice, no such priming occurred. Our data are more consistent with the idea that the face was primed, rather than a particular episodic encounter with it.

We have discussed the issue of the locus of repetition priming effects, but there remains the question of what is being primed: What information from the face is being processed by the two hemispheres? As mentioned in the Introduction, a number of workers (e.g., Bartlett \& Searcy, 1993; Collishaw \& Hole, 2000) have suggested that there are two means by which a face can be recognized: via its configural properties, or via the individual facial features. Various lines of evidence argue for this distinction. First, facial inversion seems to affect configural processing much more than it does featural processing (e.g., Bartlett \& Searcy, 1993; Murray, Yong, \& Rhodes, 2000; Searcy \& Bartlett, 1996; Young, Hellawell, \& Hay, 1987). Second, studies have shown complementary patterns of lateralization for configural and featural processing. In particular, there appears to be a right-hemisphere advantage for processing upright faces (Rhodes, 1985), for processing low-spatial-frequency information (Goffaux, Gauthier, \& Rossion, 2003; Sergent, 1986), and for whole-face processing (Rossion et al., 2000). One implication of the present findings is that face priming appears to occur only if the face receives configural processing. Priming occurred only if the right hemisphere was involved in processing, either at the initial exposure to a face or when it was presented as a prime. No priming was found in the two experimental conditions in which only the left hemisphere was involved.

The present results suggest an underlying anatomical basis for the distinction between configural and featural processing: Perhaps the former is mainly carried out by the right hemisphere, while the latter is the domain of the left hemisphere. It remains an open question precisely what "configural" and "featural" processing mean in this context. There are a number of possibilities other than the intuitively obvious one of distinguishing between subjectively salient facial features and their spatial arrangement. For example, it has been suggested that the right hemisphere performs a more global analysis of all kinds of visual stimuli (face and nonface stimuli alike), while the left hemisphere analyses stimuli at a more local level. This fits with the studies mentioned above that suggest the right hemisphere is most sensitive to low-spatial-frequency information in faces (e.g., Goffaux et al., 2003). Another possibility is that the visual system performs some form of PCA analysis on stimuli, so that faces are decomposed into a set of eigenfaces, which capture facial information at different 
scales. A number of studies in our own laboratory give us cause to believe that the right and left hemispheres differ in the extent to which they are affected by manipulations of a face's configural and featural properties (Bourne \& Hole, 2005).

The findings reported in this paper are consistent with previous research that suggests that there is a $\mathrm{RH}$ superiority for face recognition and with ERP studies that have demonstrated lateralized repetition priming. However, neither experiment found a within-hemisphere priming effect from prime faces presented to the RVF-LH. At first sight this appears to conflict with previous suggestions that both hemispheres are involved in face processing and recognition (e.g., Warrington \& James, 1967), which have suggested that the LH may take longer to process and recognize faces, but that ultimately it is as capable and accurate as the RH (e.g., Hillger \& Koenig, 1991). This apparent inconsistency may have arisen because the experiments in our paper and the previous research investigated different aspects of face processing and recognition. Previous research has typically examined the role of each hemisphere in face processing and recognition up to the point of recognition, whereas the experiments presented in this paper differ in that they examine the differing levels of activation following recognition. From combining this evidence it might be suggested that both hemispheres are capable of face processing and recognition, but that recognition has a longer lasting subsequent effect on $\mathrm{RH}$ processing and recognition than on the $\mathrm{LH}$. This explanation is consistent with previous work examining lateralized semantic processing of verbal stimuli (Koivisto, 1997). Koivisto found asymmetric hemispheric activation for a semantic priming task with longer lasting $\mathrm{RH}$ activation than LH activation. This finding is consistent with ours and lends further support to this explanation of our data. This possibility could be easily tested for by experimentally manipulating the time delay between prime and target presentation. With such a manipulation a LH priming effect may be found with shorter delays.

One possible interpretation of the experiments and findings presented in this paper is that they may reflect asymmetric picture priming rather than face-specific priming. However, priming effects were found for famous faces in both experiments, whereas nonfamous face priming did not occur. If the findings were resulting from picture priming rather than face-specific priming then equivalent priming effects would have been found for both famous and not-famous faces. Graded priming effects also are relevant to our use of the same faces at the prime and target phases of the experiment. Previous studies are consistent in demonstrating that maximal levels of repetition priming are obtained when the prime and test face images are identical, as in our study. However, the graded priming effect has demonstrated that the extent of the priming effect may be reduced by the use of different images at prime and target (e.g., Bruce \& Valentine, 1985; Brunas-Wagstaff et al., 1992; Ellis, Young, Flude, \& Hay, 1987). ERP studies have found no qualitative difference between repetition priming using the same image of a person as prime and target, and that when different images are used (Schweinberger et al., 2002), suggesting that the same mechanism underlies both priming effects. The failure to find significant priming effects for nonfamous faces is explicable in terms of the mechanism proposed for face repetition priming by the IAC model of face processing and recognition (Burton et al., 1990). This model explains priming in terms of changes in the activation levels of links between the FRU and the PIN for a primed face. Since FRUs and PINs exist only for familiar faces, the IAC model predicts that unfamiliar (and unrecognized) faces should not produce repetition priming effects.

Priming occurred in both of the across visual fields conditions in Experiment 2. The finding that a prime presented to one hemisphere can impact on the recognition of a target presented to the other suggests that the information is passed between the hemispheres. It is widely known that IHC occurs to aid processing in the brain; however, the findings presented here suggest that IHC for face recognition may be asymmetric. Transfer of information from the $\mathrm{RH}$ (prime) to $\mathrm{LH}$ (target) facilitated the 
priming effect in comparison to the within $\mathrm{LH}$ priming effect. This suggests that IHC occurred from the $\mathrm{RH}$ to the $\mathrm{LH}$ in order to aid recognition. However, a similar effect was not observed when the information was initially presented to the $\mathrm{LH}$ and then the $\mathrm{RH}$. Taken together these findings suggest that IHC to aid face recognition is asymmetric with great cooperation occurring from the $\mathrm{RH}$ to the $\mathrm{LH}$ than from the $\mathrm{LH}$ to the RH. This asymmetry can easily be explained in terms of the hemispheric superiority that exists for face recognition. The $\mathrm{RH}$ shows a strong superiority for face recognition in comparison to the LH. Therefore, it is likely that the $\mathrm{RH}$ is able to effectively recognize faces as an isolated unit, whereas it provides assistance with $\mathrm{LH}$ face recognition. Hence, there seems to be a transfer of information across the hemispheres in both directions, but with IHC occurring to a greater extent from the $\mathrm{RH}$ to the $\mathrm{LH}$.

The finding of asymmetric IHC is considered in terms of three models of IHC: the horse race model, the metacontrol model, and the transcortical cell assembly (TCA) model. The horse race model (Zaidel \& Rayman, 1994) suggests that each hemisphere functions as a relatively independent unit. Whichever hemisphere is superior at performing the task is able to complete the task more efficiently and "win the race". The metacontrol model (Hellige, 1993; Levy \& Trevarthen, 1976) suggests that the hemisphere that is specialized in processing the information required to complete a given task will always exert control over the other hemisphere and may cooperate to aid the processing of the nonspecialized hemisphere. The transcortical cell assembly model (Pulvermüller \& Mohr, 1996) suggests that learned stimuli (e.g., familiar faces) are represented by cell assemblies, distributed across both hemispheres and linked by excitatory neuronal connections. IHC aids processing by causing greater activation of transcortical cell assemblies rather than isolated, unilateral cell assemblies.

The priming effects found in the across visual fields conditions are best accounted for in terms of the transcortical cell assembly model. The horse race model suggests that both hemispheres work as relatively isolated units and that the specialized hemisphere completes the task. This theory would therefore not predict any cooperation or transfer of information between the hemispheres. The finding that information presented to one hemisphere can influence processing in the other hemisphere therefore is not consistent with the horse race model. The metacontrol model suggests that IHC only occurs in one direction, with the specialized hemisphere always exerting control over the nonspecialized hemisphere. Since the $\mathrm{RH}$ is dominant for face processing and recognition, this model would predict that priming in the across visual field conditions would only occur when the prime face was presented to the LVF-RH. However, a significant priming effect was found in both of the across conditions, suggesting that IHC is bidirectional. This argues against the metacontrol model.

The transcortical cell assembly model of IHC seems able to account to all of the findings of the second experiment presented in this paper. This model suggests that cell assemblies are distributed across both hemispheres, but that they are asymmetrically distributed, with more cell assemblies located in the specialized hemisphere. This model is therefore able to account for priming isolated within one hemisphere and distributed across both hemispheres. In both of the across visual field priming conditions there was a significant priming effect (from the one-sample $t$ tests comparing performance to 0). Although the difference between these two conditions did not reach significance there was a trend towards the priming effect being greater in the RVF-LH prime, $\mathrm{LVF}-\mathrm{RH}$ target condition.

Few data exist that are comparable to ours. However, a small number of papers have examined lateralized effects for semantic word priming. Such papers have typically reported an asymmetric priming effect with greater priming occurring in the $\mathrm{LH}$, the hemisphere specialized for language processing, than in the $\mathrm{RH}$ (Abernethy \& Coney, 1996; Berger, 1988; Collins \& Coney, 1998). This is directly in line with our finding of a lateralized priming effect in the $\mathrm{RH}$ for face recognition. The findings of experiments using across 
hemisphere semantic word priming have, however, not found results as easily compatible with ours, with greater IHC identified from the nonspecialized hemisphere $(\mathrm{RH})$ to the specialized hemisphere (LH; Abernethy \& Coney, 1996; Berger, 1988; Collins, 1999; Collins \& Coney, 1998; Koivisto \& Hämäläinen, 2002). Although this finding seems to directly contrast with ours, both show a greater IHC effect from the RH to the LH. It is possible that the asymmetry identified is a more generalized asymmetry that occurs regardless of the stimuli being processed. The asymmetric characteristics of IHC require further examination.

The finding of an across hemisphere priming effect in Experiment 2 of this paper suggests that presentation of a prime to one visual field causes subsequent activation in both hemispheres. The pattern of results in Experiment 1 could be explained if the two hemispheres differed in terms of the longevity of the heightened levels of excitatory activity. Levels of activation may remain above resting levels in the $\mathrm{RH}$ over an extended period of time, but activation in the LH may return to resting levels soon after recognition. It may therefore be that unilateral priming causes activation in both hemispheres regardless of which hemisphere the prime is presented to, but that asymmetry occurs depending on which hemisphere the target is presented to and the remaining levels of activation in that hemisphere. As such it would be predicted that more priming would occur if the target were presented to the $\mathrm{RH}$, where levels of activation remained above resting levels, and less priming if the target were presented to the $\mathrm{LH}$, where levels of activation may have returned to resting levels.

Original manuscript received 25 March 2004 Accepted revision received 3 March 2005 PrEview proof published online 10 August 2005

\section{REFERENCES}

Abernethy, M., \& Coney, J. (1996). Semantic priming in the left cerebral hemisphere. Neuropsychologia, $34,339-350$.
Bartlett, J. C., \& Searcy, J. H. (1993). Inversion and configuration of faces. Cognitive Psychology, 25, 281-316.

Begleiter, H., Porjesz, B., \& Wang, W. (1995). Event-related potentials differentiate priming and recognition to familiar and unfamiliar faces. Electroencephalography and Clinical Neurophysiology, 94, 41-49.

Bentin, S., \& Moscovitch, M. (1988). The time course of repetition effects for words and unfamiliar faces. Journal of Experimental Psychology: General, 117(2), 148-160.

Berger, J. M. (1988). Interhemispheric cooperation and activation of verbal information. Behavioural Brain Research, 29, 193-200.

Bourne, V. J., \& Hole, G. J. (2005). The role of the left hemisphere in face processing: Specialisation in featural processing. Manuscript submitted for publication.

Bruce, V., Burton, M., Carson, D., Hanna, E., \& Mason, O. (1994). Repetition priming of face recognition. In C. Umiltà (Ed.), Attention and performance $X V$ (pp. 179-201). Cambridge, MA: MIT Press.

Bruce, V., \& Valentine, T. (1985). Identity priming in the recognition of familiar faces. British Journal of Psychology, 76, 373-383.

Brunas-Wagstaff, J., Young, A. W., \& Ellis, A. W. (1992). Repetition priming follows spontaneous but not prompted recognition of familiar faces. Quarterly Journal of Experimental Psychology, 44A, 423-454.

Burton, A. M., Bruce, V., \& Johnston, R. A. (1990). Understanding face recognition with an interactive activation model. British Journal of Psychology, 81, 361-380.

Burton, A. M., Young, A. W., Bruce, V., Johnston, R. A., \& Ellis, A. W. (1991). Understanding covert recognition. Cognition, 39(2), 129-166.

Campbell, R., \& De Haan, E. H. F. (1998). Repetition priming for face speech images: Speech-reading primes face identification. British Journal of Psychology, 89, 309-323.

Collins, M. (1999). Differences in semantic category priming in the left and right cerebral hemispheres under automatic and controlled processing conditions. Neuropsychologia, 37, 1071-1085.

Collins, M., \& Coney, J. (1998). Interhemispheric communication is via direct connections. Brain and Language, 64, 28-52.

Collishaw, S. M., \& Hole, G. J. (2000). Featural and configural processes in the recognition of faces of different familiarity. Perception, 29, 893-909. 
Compton, R. (2002). Inter-hemispheric interaction facilitates face processing. Neuropsychologia, 40, 2409-2419.

Damasio, A. R., Damasio, H., \& VanHosen, G. W. (1982). Prosopagnosia: Anatomic basis and behavioural mechanisms. Neurology, 32, 321-341.

De Renzi, E., \& Spinnler, H. (1966). Facial recognition in brain-damaged patients. An experimental approach. Neurology, 16, 145-152.

Dorthe, N. J., Blumenthal, T. D., Jason, D. R., \& Lantz, P. E. (1995). The use of next-of-kin in assessing handedness. Perceptual and Motor Skills, 81, 203-208.

Dubois, S., Rossion, B., Schiltz, C., Bodart, J. M., Michel, C., Bruyer, R., et al. (1999). Effect of familiarity on the processing of human faces. Neuroimage, 9, 278-289.

Ellis, A. W., Young, A. W., \& Flude, B. M. (1990). Repetition priming and face processing-priming occurs within the system that responds to the identity of a face. Quarterly Journal of Experimental Psychology, 42A, 495-512.

Ellis, A. W., Young, A. W., Flude, B. M., \& Hay, D. C. (1987). Repetition priming of face recognition. Quarterly Journal of Experimental Psychology, 39A, 193-210.

Goffaux, V., Gauthier, I., \& Rossion, B. (2003). Spatial scale contribution to early visual differences between face and object processing. Cognitive Brain Research, 16(3), 416-424.

Goshen-Gottstein, Y., \& Ganel, T. (2000). Repetition priming for familiar and unfamiliar faces in a sexjudgment task: Evidence for a common route for the processing of sex and identity. Journal of Experimental Psychology: Learning, Memory, and Cognition, 26(5), 1198-1214.

Hancock, P. J. B., Burton, A. M., \& Bruce, V. (1996). Face processing: Human perception and principal components analysis. Memory \& Cognition, 24(1), $26-40$.

Haxby, J. V., Ungerleider, L. G., Clark, V. P., Schouten, J. L., Hoffman, E. A., \& Martin, A. (1999). The effect of face inversion on activity in human neural systems for face and object perception. Neuron, 22, 189-199.

Hellige, J. B. (1993). Hemispheric asymmetry: What's right and what's left. London: Harvard University Press.

Hillger, L. A., \& Koenig, O. (1991). Separable mechanisms in face processing: Evidence for hemispheric specialisation. Journal of Cognitive Neuroscience, 3, 42-58.
Hole, G. J. (1994). Configural factors in the perception of unfamiliar faces. Perception, 23, 65-74.

Jacoby, L. L. (1983). Perceptual enhancement: Persistent effects of an experience. Journal of Experimental Psychology: Learning, Memory, and Cognition, 9, 21-38.

Johnston, R. A., Barry, C., \& Williams, C. (1996). Incomplete faces don't show the whole picture: Repetition priming from jumbled faces. Quarterly Journal of Experimental Psychology, 49A, 596-615.

Kanwisher, N., McDermott, J., \& Chun, M. M. (1997). The fusiform face area: A module in human extrastriate cortex specialized for face perception. Journal of Neuroscience, 17, 4302-4311.

Koivisto, M. (1997). Time course of semantic activation in the cerebral hemispheres. Neuropsychologia, 35, 497-504.

Koivisto, M., \& Hämäläinen, H. (2002). Hemispheric semantic priming in the single presentation task. Neuropsychologia, 40, 978-985.

Koivisto, M., \& Laine, M. (2000). Hemispheric asymmetries in activation and integration of categorical information. Laterality, 5, 1-21.

Levy, J., Heller, W., Banich, M. T., \& Burton, L. A. (1983). Asymmetry of perception in free viewing of chimeric faces. Brain and Cognition, 2, 404-419.

Levy, J., \& Trevarthen, C. (1976). Metacontrol of hemispheric function in human split-brain patients. Journal of Experimental Psychology: Human Perception and Performance, 2, 299-312.

Lewis, M. B., \& Ellis, H. D. (1999). Repeated repetition priming in face recognition. Quarterly Journal of Experimental Psychology, 52A, 927-955.

Lewis, M. B., \& Ellis, H. D. (2000). The effects of massive repetition on speeded recognition of faces. Quarterly Journal of Experimental Psychology, 53A, 1117-1142.

Loftus, G. R., \& Masson, M. E. J. (1994). Using confidence intervals in within-subject designs. Psychonomic Bulletin and Review, 1, 476-490.

Logan, G. D. (1990). Repetition priming and automaticity-common underlying mechanisms. Cognitive Psychology, 22(1), 1-35.

Magnussen, S., Sunde, B., \& Dyrnes, S. (1994). Patterns of perceptual asymmetry in processing facial expression. Cortex, 30, 215-229.

Marotta, J. J., McKeeff, T. J., \& Behrmann, M. (2002). The effects of rotation and inversion on face processing in prosopagnosia. Cognitive Neuropsychology, 19, $31-47$. 
McCarthy, G., Puce, A., Gore, J. C., \& Allison, T. (1997). Face-specific processing in the human fusiform gyrus. Journal of Cognitive Neuroscience, 9, 605-610.

Mohr, B., Landgrebe, A., \& Schweinberger, S. R. (2002). Interhemispheric cooperation for familiar but not unfamiliar face processing. Neuropsychologia, 40, 1841-1848.

Murray, J. E., Yong, E., \& Rhodes, G. (2000). Revisiting the perception of upside-down faces. Psychological Science, 11(6), 492-496.

Pfütze, E. M., Sommer, W., \& Schweinberger, S. R. (2002). Age-related slowing in face and name recognition: Evidence from event-related brain potentials. Psychology and Aging, 17, 140-160.

Puce, A., Allison, T., Asgari, M., Gore, J. C., \& McCarthy, G. (1996). Differential sensitivity of human visual cortex to faces, letterstrings, and textures: A functional magnetic resonance imaging study. Journal of Neuroscience, 16, 5205-5215.

Pulvermüller, F., \& Mohr, B. (1996). The concept of transcortical cell assemblies: A key to the understanding of cortical lateralization and interhemispheric interaction. Neuroscience and Biobehavioral Reviews, 20, 557-566.

Rakover, S. S. (2002). Featural vs. configurational information in faces: A conceptual and empirical analysis. British Journal of Psychology, 93, 1-30.

Rhodes, G. (1985). Lateralized processes in face recognition. British Journal of Psychology, 76, 249-271.

Roediger, H. L., \& Blaxton, T. A. (1987). Effects of varying modality, surface-features, and retention interval on priming in word-fragment completion. Memory E Cognition, 15(5), 379-388.

Rossion, B., Dricot, L., Devolder, A., Bodart, J. M., Crommelinck, M., de Gelder, B., et al. (2000). Hemispheric asymmetries for whole-based and part-based face processing in the human fusiform gyrus. Journal of Cognitive Neuroscience, 12(5), 793-802.

Schweinberger, S. R., Baird, L. M., Blumler, M., Kaufmann, J. M., \& Mohr, B. (2003).
Interhemispheric cooperation for face recognition but not for affective facial expressions. Neuropsychologia, 41, 407-414.

Schweinberger, S. R. W. (1995). Repetition priming of face recognition: Evidence from event-related potentials. Journal of Experimental Psychology: Learning, Memory, and Cognition, 21, 722-736.

Schweinberger, S. R., Pickering, E. C., Burton, A. M., \& Kaufmann, J. M. (2002). Human brain potential correlates of repetition priming in face and name recognition. Neuropsychologia, 40, 2057-2073.

Searcy, J. H., \& Bartlett, J. C. (1996). Inversion and processing of component and spatial-relational information in faces. Journal of Experimental Psychology: Human Perception and Performance, 22, 904-915.

Sergent, J. (1986). Microgenesis of face perception. In H. D. Ellis, M. A. Jeeves, F. Newcombe, \& A. W. Young (Eds.), Aspects of face processing. Dordrecht, Netherlands: Martinus Nijhoff.

Uttner, I., Bliem, H., \& Danek, A. (2002). Prosopagnosia after unilateral right cerebral infarction. Journal of Neurology, 249, 933-935.

Warrington, E. K., \& James, M. (1967). An experimental investigation of facial recognition in patients with unilateral cerebral lesions. Cortex, 3, 317-326.

Young, A. W. (1982). Methodological theoretical bases. In J. G. Beaumont (Ed.), Divided visual field studies of cerebral organisation (pp. 11-27). London: Academic Press.

Young, A. W., Hay, D. C., McWeeny, K. H., Ellis, A. W., \& Barry, C. (1985). Familiarity decisions for faces presented to the left and right cerebral hemispheres. Brain and Cognition, 4, 439-450.

Young, A. W., Hellawell, D. J., \& Hay, D. C. (1987). Configural information in face perception. Perception, 16, 747-759.

Zaidel, E., \& Rayman, J. (1994). Interhemispheric control in the normal brain-evidence from redundant bilateral presentations. In C. Umiltà (Ed.), Attention and performance XV (pp. 477-504). Cambridge, MA: MIT Press. 